\title{
ELEMENTOS PARA UMA POLÍTICA DE APOIO AO SISTEMA REGIONAL DE INOVAÇÃO DO ESTADO DO RIO DE JANEIRO: UMA ANÁLISE COM BASE NA ABORDAGEM DA GEOGRAFIA ECONÔMICA EVOLUCIONÁRIA
}

\author{
Guilherme de Oliveira Santos* \\ Renata Lèbre La Rovere**
}

\begin{abstract}
Resumo: O Estado do Rio de Janeiro (ERJ) abriga um expressivo conjunto de organizações e instituições voltadas à geração de conhecimento científico e tecnológico, bem como ainda conserva uma base industrial relativamente complexa. Entretanto, o Estado apresenta deficiências em converter os seus recursos humanos e financeiros em uma performance inovativa compatível. A abordagem da Geografia Econômica Evolucionária (GEE) aponta que os sistemas regionais de inovação estão sujeitos a diferentes falhas sistêmicas que justificam a elaboração de políticas de apoio à inovação. Neste sentido, este artigo, com base no referencial teórico proposto pela GEE, tem como objetivo principal discutir as falhas do sistema de inovação fluminense, bem como identificar quais elementos são mais relevantes para uma política de apoio ao sistema regional de inovação. Para tanto, com base no referencial foram definidas as falhas sistêmicas a serem discutidas no artigo. Em seguida, selecionamos os dados capazes de dar suporte à análise de cada uma das falhas selecionadas. Além disso, utilizamos trechos de entrevistas realizadas pelos autores em $2015 \mathrm{com}$ gerentes das principais instituições de apoio à inovação e ao empreendedorismo localizadas no ERJ para corroborar os achados da discussão. Em síntese, o artigo concluiu que o sistema de inovação fluminense possui falhas sistêmicas ligadas à limitação na atividade de P\&D; aos efeitos de lock-in; às falhas de aprendizado e as na capacidade de absorção das firmas; às falhas nas complementaridades dinâmicas; e aos trade-offs entre criação e difusão de inovações. Neste sentido, propõe-se uma política de apoio ao sistema estadual de inovação centrada na diversificação da atividade inovadora e na melhora da capacidade inovativa das empresas; na articulação das diversas instituições de fomento; na promoção do empreendedorismo dentro das empresas; e no fomento à inovação nas instituições científico-tecnológicas do Estado.
\end{abstract}

Palavras-Chave: Estado do Rio de Janeiro; Sistema Regional de Inovação; Geografia Econômica Evolucionária.

\begin{abstract}
The State of Rio de Janeiro has a large set of scientific and technologic institutions, as well as still preserve a relatively complex industrial basis. However, the State has shortcomings in converting human and financial resources to a consistent innovative performance. The Evolutionary Economic Geography (EEG) approach indicates that regional innovation systems are subject to different systemic failures which justify the elaboration of innovation policies. This way, this article, based on the theoretical background proposed by EEG, aims at analysing the systemic failures of the State of Rio de Janeiro innovation system and identifying the main elements which are necessary for a policy to support the regional innovation system. For this purpose, based on the theoretical backgroud, we defined the system failures to be discussed. Aftewards, we selected the adequate data to support the analysis of each chosen failure. Moreover, we used part of the interviews we carried out in 2015 with managers of the main support institutions for innovation and entrepreneurship placed in the State of Rio de Janeiro to endorse the findings. In short, the paper concluded that the State of Rio de Janeiro innovation system has systemic failures related to the limitation in R\&D activities; lock-in effects; failures concerning learning and the firms' absortive capacity; failures concerning dynamics complementarities; and trade-offs between creation and diffusion of innovation. That way, we suggest a policy to support the regional innovation system centered on the diversification of innovation activity and the improvement of firms' innovative capacity; the articulation among different funding agencies; the promotion of entrepreneurship within companies; and the encouragement of innovation in the State's scientific and technologic institutions.
\end{abstract}

Keywords: State of Rio de Janeiro; Regional Innovation System; Evolutionary Economic Geography.

Área 4.3: Sistemas de inovação - nacional, regional, setorial, tecnológico

JEL: L38; O30; R58

\footnotetext{
*Doutorando no Programa de Pós Graduação em Políticas Públicas, Estratégias e Desenvolvimento (PPED) do Instituto de Economia da UFRJ (IE/UFRJ), Bolsista CNPq, e pesquisador do Grupo de Pesquisa Economia de Inovação do IE/UFRJ. Contato: guilhermedeoliveirasantos.gos@gmail.com
}

\footnotetext{
** Doutora pela Université Paris 7. Professora do Instituto de Economia da Universidade Federal do Rio de Janeiro. Contato: renata@ie.ufrj.br
} 


\section{INTRODUÇÃO}

A economia do Estado do Rio de Janeiro (ERJ) passou por sucessivas crises na segunda metade do século XX, tendo como ápice os anos 1980, em virtude do declínio expressivo da produção industrial na Região Metropolitana. A situação começou a ser revertida em meados dos anos 1990, a partir da descoberta das maiores reservas nacionais de petróleo na bacia de Campos dos Goytacazes, no Norte Fluminense, atraindo grandes investimentos para a região com reflexos no restante do Estado (La Rovere e Paranhos, 2011; Sobral, 2012). Não obstante alguns autores apostarem em uma "inflexão econômica positiva" (Santos, 2002; Natal, 2004), este diagnóstico não se comprovou nos anos seguintes. A economia do Petróleo e Gás conquistou um peso desproporcional na economia do ERJ, que se tornou fortemente especializada e presa a uma armadilha de baixo dinamismo econômico. O avanço espetacular da indústria extrativa, no entanto, contrastou com as perdas significativas observadas em quase todos os setores da indústria de transformação. Paralelamente, o setor de serviços fluminense se caracteriza por serviços de baixo valor agregado, sendo dominado por serviços prestados às famílias. Além disso, a fraca integração territorial da RMRJ com o interior do Estado contribuiu para a desintegração do tecido produtivo, e consequentemente gerou uma "estrutura produtiva oca" (Sobral, 2012; 2017), dificultando a integração de cadeias produtivas ancoradas na base industrial relativamente sofisticada que ainda possui o Rio de Janeiro (Hasenclever et al., 2012).

Apesar disso, o Rio de Janeiro abriga um expressivo conjunto de organizações e instituições voltadas à geração de conhecimento científico e tecnológico, bem como ainda conserva uma base industrial relativamente complexa. Entretanto, evidências sinalizam que o ERJ apresenta deficiências em converter os seus recursos humanos e financeiros em uma performance inovativa compatível, em razão da desarticulação dos atores que compõem o sistema de inovação do Estado (Porto et al., 2012; Marcellino et al., 2013; Britto, Cassiolato e Marcellino 2015).

Neste contexto, a inovação e sua difusão no conjunto da economia fluminense são elementos cruciais para a construção de uma trajetória sustentável de desenvolvimento no Estado. No entanto, as políticas e estratégias de apoio à inovação que se limitam a reproduzir fórmulas prontas desenhadas em outros contextos são ineficazes. Recentemente, a geografia econômica está buscando incorporar contribuições da teoria evolucionária para analisar o desenvolvimento regional e auxiliar na formulação de políticas regionais de inovação que sejam adequadas ao contexto em que serão implementadas. Desta feita, a abordagem da Geografia Econômica Evolucionária (GEE) aponta que os sistemas regionais de inovação estão sujeitos a diferentes falhas sistêmicas que justificam a elaboração de políticas de apoio à inovação. Neste sentido, este artigo, tendo como base o referencial proposto pela GEE, busca responder duas perguntas: Quais são as falhas do sistema de inovação fluminense? Quais os elementos mais relevantes para uma política de apoio ao sistema regional de inovação?

Para tanto, foi realizada uma pesquisa bibliográfica para construir o referencial teórico sobre Geografia Econômica Evolucionária e Política Regional de Inovação. Com base neste referencial foram definidas as falhas do sistema regional de inovação a serem discutidas no artigo, sendo elas: i) limites na atividade de P\&D e efeitos de lock-in; ii) falhas de aprendizado e de capacidade de absorção; iii) falhas nas complementaridades dinâmicas; e iv) trade-offs entre inovação e difusão. Em seguida, selecionamos os dados capazes de dar suporte a análise de cada uma das falhas selecionadas. Foi feito um levantamento de dados em fontes primárias e secundárias, incluindo pesquisas oficiais realizadas pelo IBGE, bem como artigos científicos e relatórios de pesquisa. Além disso, utilizamos trechos de entrevistas realizadas pelos autores em 2015 com gerentes das principais instituições de apoio à inovação e ao empreendedorismo localizadas no ERJ - BNDES, FINEP, SEBRAE-RJ e IEL -, para corroborar os achados da discussão. Finalmente, concluímos o artigo propondo diretrizes de políticas de suporte ao sistema regional de inovação.

Em síntese, o artigo concluiu que o sistema de inovação fluminense possui falhas sistêmicas ligadas à limitação na atividade de $\mathrm{P} \& \mathrm{D}$, dominada por grandes empresas; aos efeitos de lock-in, 
caracterizados pela forte especialização e dependência em torno da cadeia do Petróleo e Gás; às falhas de aprendizado e capacidade de absorção das firmas, que apresentam esforços inovativos limitados e dificuldade de absorver mão de obra qualificada; às falhas nas complementaridades dinâmicas, decorrentes da falta de articulação das redes de inovação localizadas no Estado; e a trade-offs entre criação e difusão de inovações, resultantes da falta de articulação entre oferta e demanda de capacitação e do fato de que as empresas apostam mais no aproveitamento de conhecimentos existentes do que no desenvolvimento de novos conhecimentos. Com base neste diagnóstico, propõe-se que uma política de apoio ao sistema estadual de inovação deve se centrar na diversificação da atividade inovadora e na melhora da capacidade inovativa das empresas; na articulação das diversas instituições de fomento; na promoção do empreendedorismo dentro das empresas; e no fomento à inovação nas instituições científico-tecnológicas do Estado.

O artigo está dividido em cinco seções, além desta introdução. A segunda seção retrata o contexto da economia do Estado do Rio de Janeiro nas últimas décadas; a terceira seção apresenta o referencial teórico acerca da abordagem da Geografia Econômica Evolucionária e sua implicação para Política Regional de Inovação; a quarta seção detalha a metodologia; a quinta seção dedica-se à discussão das falhas sistêmicas do sistema de inovação fluminense; e a última seção busca apontar os elementos para uma política de apoio ao sistema de inovação do ERJ.

\section{CONTEXTO DA ECONOMIA DO ESTADO DO RIO DE JANEIRO NAS ÚLTIMAS DÉCADAS}

Historicamente, o Rio de Janeiro se estruturou como um espaço de articulação nacional, derivando inicialmente seu dinamismo econômico-social do fato de ser o principal porto brasileiro e centro militar, e posteriormente, de ser a capital da República e centro cultural político e econômico como sede do poder, centro financeiro do país e sede de empresas públicas e privadas que atuam no território brasileiro e mesmo latino-americano. Nesta trajetória, apesar do conjunto da cidade do Rio de Janeiro e do antigo Estado do Rio de Janeiro perder a hegemonia industrial para o Estado de São Paulo a partir de 1920, a região manteve um dinamismo econômico próximo ao da média brasileira até os anos 1960 (Lessa, 2000; Osório, 2013).

Entretanto, na segunda metade do século XX sucessivas crises afetaram significativamente a economia do Estado do Rio de Janeiro. A transferência da capital para Brasília (1961) e a fusão dos Estados da Guanabara e do Rio de Janeiro (1974) inauguraram este processo, que teve seu ápice nos anos 1980 com o declínio expressivo da produção industrial na Região Metropolitana do Rio de janeiro (RMRJ). A situação começou a se reverter em meados dos anos 1990, com a descoberta das maiores reservas de petróleo do país na bacia de Campos dos Goytacazes, no norte fluminense, atraindo grandes investimentos para a região com consequências para o resto do Estado, em áreas como petroquímica, indústria naval, siderurgia e metalurgia, e mais recentemente investimentos em infraestrutura urbana, rodovias e transporte público (La Rovere e Paranhos, 2011; Hasenclever et al., 2012).

A conjugação de grandes fluxos de investimento e o surgimento de fronteiras de expansão no interior levaram muitos autores a apostarem em uma "inflexão econômica positiva" (Santos, 2002; Natal, 2004) para o Estado, diagnóstico que não se comprovou nos anos seguintes. A economia do Petróleo e Gás conquistou um peso desproporcional na economia do ERJ, que se tornou fortemente especializada e presa a uma armadilha de baixo dinamismo econômico. O avanço espetacular da indústria extrativa, no entanto, contrastou com as perdas significativas observadas em quase todos os setores da indústria de transformação, indicando uma desindustrialização relativa (Sobral, 2012; 2013). Paralelamente, o setor de serviços fluminense se caracteriza por serviços de baixo valor agregado, sendo dominado por serviços prestados às famílias, a despeito da capacidade que o Estado possui para desenvolver serviços dinâmicos, fundamentais para o desenvolvimento industrial, dado o elevado grau de escolaridade da sua mão de obra (Hasenclever et al., 2012). 
Além disso, a fraca integração territorial da RMRJ com o interior do Estado contribuiu para a desintegração do tecido produtivo, e consequentemente gerou uma "estrutura produtiva oca". (Sobral, 2013; 2017). Desta forma, apesar de existirem brechas para ganhos de competitividade em nichos setoriais isolados, não se enfrentam os problemas estruturais, impedindo o surgimento de vantagens competitivas sistêmicas. Por essa razão, os grandes investimentos que fluíram para o ERJ nos últimos anos encontraram barreiras logísticas e tecnológicas para impulsionar a integração de cadeias produtivas ancoradas na base industrial relativamente sofisticada que ainda possui o Rio de Janeiro, e integrá-la com outros Estados, principalmente São Paulo (Hasenclever et al., 2012).

A despeito deste quadro adverso, o ERJ possui potencialidades para desenvolver uma trajetória de desenvolvimento econômico sustentável baseada em inovação. Por um lado, o Estado do Rio de Janeiro possui um conjunto expressivo de organizações e instituições voltadas à geração de conhecimento científico-tecnológico, com destaque para importantes universidades, institutos de pesquisa públicos e privados, e centros de $\mathrm{P} \& \mathrm{D}$ de grandes empresas (Porto et al., 2012).Por outro lado, apesar da perda de dinamismo recente, o ERJ conserva uma base industrial relativamente complexa. Apesar de sua frágil integração territorial e consequente esgarçamento do seu tecido produtivo, incapaz de constituir uma integração produtiva qualificada, o peso da indústria fluminense a nível nacional ainda é significativa. Além da cadeia do P\&G, o Rio de Janeiro destacase também em setores como a metalurgia básica, metal-mecânica, farmacêutica, bebidas e construção naval (La Rovere et al., 2015); além de ter potencial nos setores de tecnologia da informação, produção de automóveis e economia criativa (FIRJAN, 2014).

No entanto, evidências sinalizam que o ERJ apresenta deficiências em converter os volumosos recursos humanos e financeiros, em uma performance inovativa compatível. Marcellino et al. (2013) indicam que o sistema de inovação fluminense possui um "elo fraco" nas interações entre o subsistema de geração de conhecimento - infraestrutura de C\&T - e o subsistema de exploração de conhecimento - setor produtivo -, dificultando a transmissão de conhecimento e a transferência de tecnologias, e tornando o processo inovativo mais árduo e menos efetivo para as empresas integrantes do sistema. Este hipótese é reforçada no estudo de Porto et al.(2012) sobre o sistema estadual de inovação fluminense. Os autores salientam que a falta de articulação nas políticas públicas e a incapacidade de interação das empresas com os institutos de pesquisa e universidades são capazes de explicar a baixa de integração tecnológica da economia fluminense.

Neste contexto, o estímulo à inovação e sua difusão no conjunto da economia fluminense são elementos cruciais para a diversificação da economia, e a consequente redução de sua dependência do setor de petróleo e gás, bem como pré-requisitos para que as firmas localizadas no Estado aumentem o valor de sua produção e se tornem mais competitivas tanto nacional como internacionalmente. Entretanto, as estratégias de apoio à inovação que se limitam a reproduzir fórmulas prontas desenhadas em outros contextos são ineficazes. Recentemente, a geografia econômica está buscando incorporar contribuições da teoria evolucionária para analisar o desenvolvimento regional e pensar em políticas regionais de inovação que sejam adequadas ao contexto em que serão implementadas.

\section{IMPLICAÇÕES DA ABORDAGEM DA GEOGRAFIA ECONÔMICA EVOLUCIONÁRIA PARA A POLÍTICA REGIONAL DE INOVAÇÃO}

Inserido no arcabouço teórico da economia evolucionária, o enfoque em Sistemas de Inovação defende que a diversidade de capacitações acumuladas pelas firmas e a sua capacidade de aprendizado são fundamentais para o seu sucesso econômico, e se preocupa em analisar como diferentes estruturas institucionais afetam a introdução e difusão de novidades na economia (Freeman, 1987; Lundvall, 1992). Em linhas gerais, a ideia básica do conceito de Sistemas de Inovação é que o desempenho inovativo depende não apenas do desempenho de empresas e organizações de ensino e pesquisa, mas também de como elas interagem entre si e com vários outros atores, e como as instituições - inclusive as políticas - afetam o desenvolvimento dos sistemas. Entende-se, deste modo, que os processos de inovação que ocorrem no âmbito da empresa 
são, em geral, gerados e sustentados por suas relações com outras empresas e organizações, ou seja, a inovação consiste em um fenômeno sistêmico e interativo, caracterizado por diferentes tipos de cooperação (Cassiolato e Lastres, 2005).

Apesar do conceito de Sistema de Inovação ter sido concebido e ser mais utilizado em escala nacional, é possível utilizá-lo em uma dimensão espacial menor. Como apontado por Lundvall et al.(2002), o conceito de Sistema Nacional de Inovação se difundiu rapidamente nos anos 90 do século passado, não apenas entre acadêmicos como também entre policymakers. Paralelamente, foram desenvolvidos estudos propondo o conceito de Sistema Regional de Inovação (Cooke 1992; Maskell e Malmberg 1999; Cooke et al., 2007). Além de considerar os processos interativos de aprendizado tecnológico e a criação e difusão de conhecimento ao longo da estrutura produtiva, o foco em Sistemas Regionais de Inovação (SRI) agrega na análise elementos como a dimensão territorial - grau de enraizamento; a proximidade geográfica como alavanca para o intercâmbio de informações e experiências que favorece a transmissão de conhecimento tácito; os padrões particulares de articulação com o mercado; e as estruturas e mecanismos de coordenação, com ênfase no conjunto de instituições locais.

Mais recentemente, Grabher (2009) aponta que a geografia econômica está passando por uma "virada evolucionária", reforçando a crença de que as experiências e competências adquiridas ao longo do tempo por indivíduos e entidades em localidades particulares determinam em grande medida as configurações presentes da região, bem como suas trajetórias futuras (Kogler, 2015). A chamada Geografia Econômica Evolucionária (GEE), que combina insights de diversos campos teóricos relacionados - como a ciência regional e a geografia da inovação (Feldman e Kogler, 2010) - vem se consolidando como um framework de pesquisa promissor e em rápida evolução. $\mathrm{O}$ foco nas forças motrizes dos processos de desenvolvimento regional em suas diferentes dimensões (micro, meso e macro), bem como a tentativa de traduzir os achados acerca do desenvolvimento desigual e suas consequências relativas em políticas públicas, são os principais tópicos de pesquisa trabalhados por esta vertente teórica (Kogler, 2015).

Neste prisma, alguns autores estão buscando situar o debate acerca das políticas regionais de inovação dentro do quadro analítico fornecido pela GEE. De forma mais ampla, Malerba e Torrisi (2009) apontam que uma política de apoio a um sistema de inovação sob uma perspectiva evolucionária deve se desenvolver quando o sistema apresenta os seguintes limites e escolhas: 1) falhas nos processos de aprendizado das firmas ligadas a baixa capacidade de absorção, limites na atividade de $\mathrm{P} \& \mathrm{D}$ ou efeitos de lock-in; 2) falhas no desenvolvimento de complementaridades dinâmicas necessárias a sustentar o desenvolvimento e a difusão de novas tecnologias; 3) trade-offs entre inovação e difusão tecnológica, entre variedade e seleção, entre desenvolvimento de novo conhecimento e aproveitamento do estoque de conhecimentos existente.

Mais especificamente, Coenen et al. (2016) apontam diversas falhas sistêmicas estruturais, que condicionam e moldam as políticas públicas para inovação orientadas pela visão de sistema, entre os quais: i) Falha das Capacidades: falta de recursos e competências apropriadas no nível da firma e das organizações que podem limitar e/ou prevenir a geração de, acesso ao, e exploração de conhecimento; ii) Falha de Infraestrutura: falta de infraestruturas física e de conhecimento devido à larga escala, longo tempo de operação, e finalmente, baixo retorno do investimento para investidores privados; iii) Falha das Instituições "Duras" (hard): ausência, excesso ou deficiências das instituições formais, tais com leis, regulações e padrões; iv) Falha das Instituições "Leves" (soft): falta de instituições informais, tais como normas e valores sociais, cultura, espírito empreendedor, confiança e tomada de risco, que impedem a colaboração necessária à inovação; v) Falha das Redes "Fortes" (strong networks): cooperação intensiva em redes intimamente ligadas pode levar à miopia e limitação do fluxo de novas ideias; vi) Falha das Redes "Fracas" (weak networks): interações e trocas de conhecimento muito limitadas com outros atores inibem a exploração de fontes de conhecimentos complementares e processos de aprendizado interativo. 
Neste sentido, Coenenet al.(2016) sinalizam que a noção de política mais clara proveniente do "casamento" entre SRI e GEE seria o conceito de Vantagem Regional Construída (Constructing Regional Advantage, no original em inglês). Essa abordagem advoga uma intervenção de política para promover a diversificação econômica das regiões através de políticas feitas sob medida baseadas na proximidade (relatedness) entre indústrias, e na combinação de bases de conhecimento no contexto da cooperação público-privada.

De maneira semelhante, Boschma e Frenken (2009) argumentam que uma política regional evolucionária deve ter como ponto de partida a especificidade do contexto local e da estrutura industrial. Neste sentido, Boschma (2009) sinaliza que uma intervenção pública não deve aplicar frameworks do tipo "one-size-fits-all" (Tödtling e Trippl, 2005), e nem políticas focadas em "escolher vencedores". Ao invés disso, as políticas devem levar em conta a história de cada região, identificando os gargalos e os potenciais da região. Além disso, as políticas devem ter como objetivo fortalecer a conexão entre os elementos do sistema regional, consolidando as estruturas existentes. Não obstante, para evitar o efeito lock-in é crucial que a política utilize instrumentos experimentais e dê espaço para novos atores.

Aprofundando-se neste debate, Boschma (2009) defende que os formuladores de política devem agir como intermediários (ou "brokers") de conhecimento, ou estabelecer plataformas de políticas que estimulem o conhecimento a transbordar e ser difundido entre setores relacionados entre si. Este tipo de política focada na construção de redes, no entanto, deve levar em consideração que as redes de conhecimento frequentemente perpassam as fronteiras das regiões (Gertler e Levitte, 2005; Giuliani, 2005). Neste contexto, as universidades podem desempenhar um papel fundamental na exploração de links inter-regionais, na medida em que, geralmente, as mesmas são extremamente bem conectadas com as redes internacionais (Boschma, 2009).

\section{METODOLOGIA}

O estímulo à inovação e sua difusão no conjunto da economia fluminense desempenham papel chave na superação da armadilha de baixo dinamismo econômico em que o Estado está preso, bem como na consolidação de uma trajetória sustentável de desenvolvimento. Apesar de possuir grande parte dos elementos necessários para a existência de um Sistema de Inovação (SI) dinâmico, o ERJ ainda apresenta uma performance inovativa aquém do seu potencial. Neste sentido, este artigo tem como objetivo principal discutir as falhas do sistema de inovação fluminense, com base no referencial proposto pela Geografia Econômica Evolucionária. Além disso, o artigo também visa identificar quais elementos são mais relevantes para uma política de apoio ao sistema regional de inovação.

Para tanto, em primeiro lugar fizemos uma revisão bibliográfica por meio de artigos científicos, livros, teses e dissertações com intuito de retratar o contexto da economia do ERJ nas últimas décadas. O referencial teórico sobre Geografia Econômica Evolucionária e Política Regional de Inovação também foi construído por meio de uma revisão bibliográfica. Utilizamos o Portal de Periódicos da CAPES para fazer um levantamento em revistas internacionais indexadas. As buscas foram guiadas pelos seguintes termos: "Evolutionary Economic Geography" e "Regional Innovation Policy", e seus correspondentes em português. Foram considerados somente os periódicos revisados por pares e com fator de impacto maior que 1, e os artigos publicados nos últimos cinco anos. Com base no referencial teórico definimos as falhas do sistema regional de inovação a serem discutidas no artigo, sendo elas: i) limites na atividade de P\&D e efeitos de lockin; ii) falhas de aprendizado e de capacidade de absorção; iii) falhas nas complementaridades dinâmicas; e iv) trade-offs entre inovação e difusão.

Após determinarmos as falhas sistêmicas que serão alvo da nossa discussão, selecionamos os dados capazes de dar suporte a análise de cada uma das falhas selecionadas. O levantamento e a compilação dos dados combinou a pesquisa em fontes primárias e secundárias, incluindo pesquisas oficiais realizadas pelo IBGE, bem como artigos científicos e relatórios de pesquisa. Munidos com 
os dados necessários partimos para a discussão das falhas do sistema de inovação fluminense. Para corroborar os achados da discussão levantada pela literatura, utilizamos trechos de entrevistas sobre realizadas pelos autores em 2015 com oito gerentes das principais instituições de apoio à inovação e ao empreendedorismo localizadas no ERJ - BNDES, FINEP, SEBRAE-RJ e IEL. Por fim, com base nos resultados, concluímos o artigo propondo diretrizes de políticas de suporte ao sistema regional de inovação.

\section{DISCUSSÃO: FALHAS SISTÊMICAS DO SISTEMA DE INOVAÇÃO FLUMINENSE}

\subsection{Limites na Atividade de P\&D e Efeitos de lock-in}

A descoberta de grandes reservas de petróleo na bacia de Campos dos Goytacazes, no norte fluminense, em meados dos anos 1990 impulsionou a retomada da trajetória de crescimento da economia fluminense. Um dos principais pilares desta retomada foi o desempenho da indústria entre 1995 e 2012 sua participação no Valor Adicionado Bruto (VAB) total do Estado passou de $19,55 \%$ para 32,19\%. Entretanto, analisando mais detalhadamente a evolução da participação da indústria neste período, nota-se que a maior parte do seu crescimento está alicerçada no avanço espetacular da indústria extrativa, sobretudo a partir de 2004. Sua participação no VAB total passa de 1,25\% em 1995 para 17,65\% em 2012 - sendo responsável neste ano por mais da metade do VAB da indústria fluminense. Paralelamente, a indústria de transformação que cresce $2,16 \%$ entre 1995 e 2004, sofre sucessivas quedas após este período, participando em 2012 com apenas 7,1\% do VAB industrial do ERJ - menos de $1 / 4$ do total (ver Gráfico 1).

Gráfico1: Participação (\%) do total da Indústria, Indústria Extrativa e Indústria de Transformação no valor adicionado bruto a preço básico no Estado do Rio de Janeiro, 1995/2012

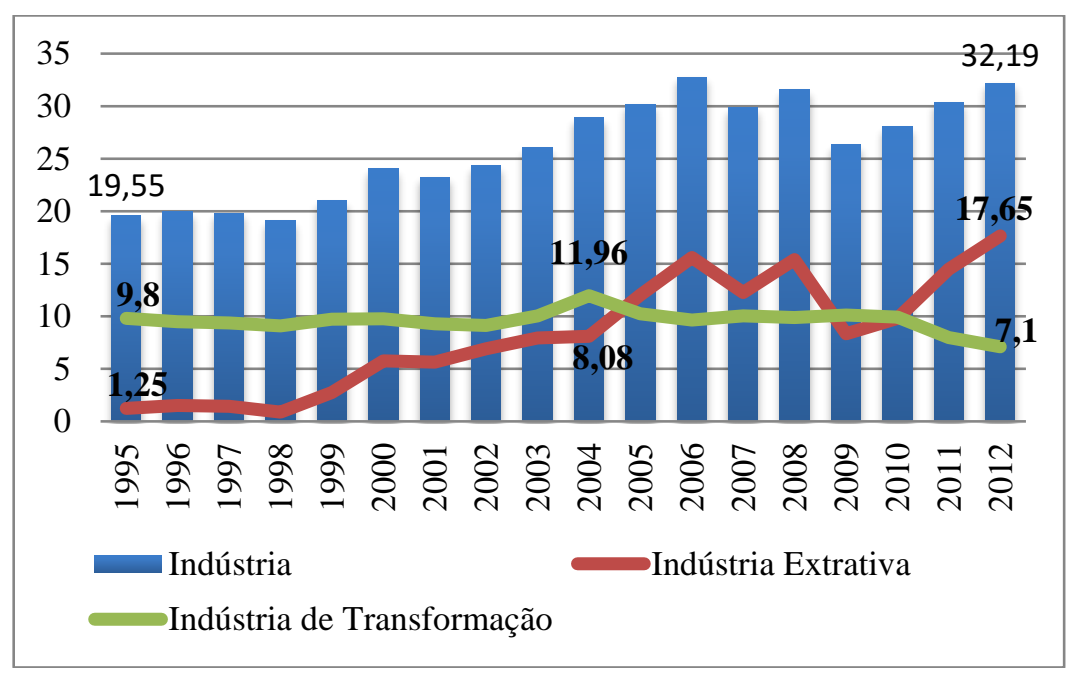

Fonte: Fundação CEPERJ

Segundo Sobral (2012, 2013), a expansão da economia do ERJ foi determinada, sobremaneira, pela plataforma de recursos naturais disponíveis e pela atração de empreendimentos industriais intensivos em escala. Desta feita, tal expansão se caracterizou por um baixo dinamismo, resultante da conjugação de dois fatores: peso da indústria extrativa, menos importante na criação de riqueza e com baixo grau de agregação de valor; e alta taxa de concentração industrial. De fato, estudo de Britto e Marcellino (2014) mostrou que em 2011 apenas dois setores (Extração de Petróleo e Serviços Relacionados e Produtos Derivados do Petróleo) foram responsáveis pela geração de 53,9\% do Valor de Transformação Industrial (VTI) total do Estado.

Para tornar a análise mais aprofundada, buscamos analisar os esforços inovativos das empresas industriais fluminenses com base na PINTEC ${ }^{1}$. Nesta seção vamos nos ater aos esforços de P\&D,

\footnotetext{
${ }^{1}$ Pesquisa de Inovação Tecnológica realizada pelo IBGE a cada três anos. Os triênios em que a pesquisa foi feita e que os resultados já foram divulgados são: 2001-2003; 2003-2005; 2006-2008; 2009-2011; 2012-2014.
} 
com foco em dois indicadores: firmas com gastos em P\&D/total das firmas e gastos em $\mathrm{P} \& \mathrm{D} /$ receita total. Considerando o percentual de firmas com gastos em P\&D (ver Gráfico 2), o ERJ apresenta uma trajetória instável. Nos dois primeiros triênios, o Estado encontrava-se em posição inferior ao total do Sudeste e do país, e nos dois seguintes o desempenho fluminense foi superior ao de ambos. Entretanto, na PINTEC 2014 o ERJ teve uma queda significativa, registrando somente $3,8 \%$ de firmas com gastos em P\&D - menor valor de toda a série histórica -, contra 5,4\% no Sudeste e $5,01 \%$ no país.

Gráfico2: Firmas com Gastos em P\&D/Total das Firmas nas Indústrias Extrativas e de Transformação no Brasil, Rio de Janeiro e Sudeste nos períodos 2001-2003, 2003-2005, 2006-2008, 2009-2011, 2012-2014

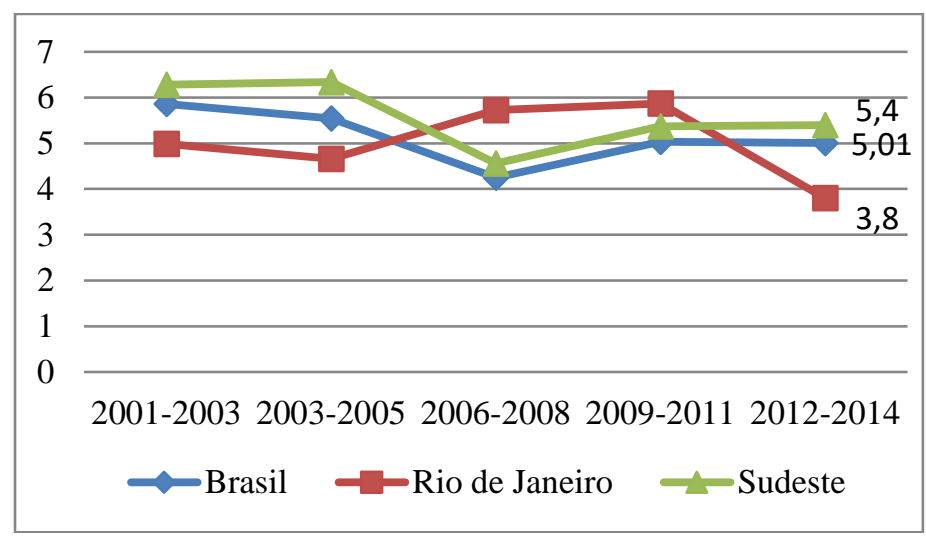

Fonte: PINTEC/IBGE

Se analisarmos o percentual de gastos em P\&D em relação à receita total (ver Gráfico 3) o desempenho fluminense é um pouco melhor. Nos três primeiros triênios analisados a performance do ERJ é bastante semelhante à do Sudeste e do país: em torno de 0,55\% no triênio 2001-2003; 0,62\% em 2003-2005; e 0,68\% em 2006-2008. No triênio 2009-2011 o Rio de Janeiro avançou 0,45 p.p., atingindo $1,16 \%$ de gastos em $\mathrm{P} \& \mathrm{D}$ sobre a receita total, resultado muito superior ao do Sudeste $(0,82 \%)$ e do Brasil $(0,71 \%)$. No último triênio, entretanto, o desempenho fluminense teve uma queda expressiva, chegando a $0,75 \%$, e voltou a convergir com os resultados do Sudeste e do Brasil, que apresentaram $0,74 \%$ e $0,67 \%$ de gastos em P\&D sobre a receita total respectivamente.

Gráfico3: Gastos em P\&D/Receita Total nas indústrias extrativas e de transformação no Brasil, Rio de Janeiro e Sudeste nos períodos 2001-2003, 2003-2005, 2006-2008, 2009-2011, 2012-2014

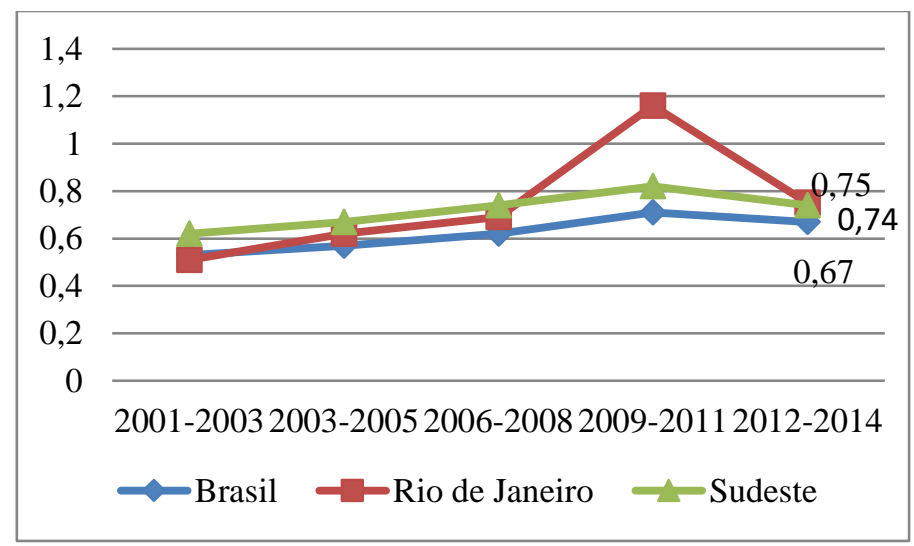

Fonte: PINTEC/IBGE

Como salientam Britto e Marcellino (2014), este padrão de gastos em P\&D reflete a presença de grandes empresas com sede no Estado, com destaque para a Petrobras, que realizam dispêndios absolutos elevados em atividades de P\&D e mobilizam um quantitativo elevado de pessoal em dedicação exclusiva nessas atividades. Nos últimos dois triênios, os gastos em P\&D, que no caso do Rio de Janeiro estão vinculados significativamente ao setor de Petróleo e Gás (P\&G), representavam quase dois terços dos gastos inovativos totais realizados pela indústria fluminense. No entanto, estes esforços de P\&D são conduzidos principalmente por empresas de grande porte, 
com destaque para as que atuam na área de $\mathrm{P} \& \mathrm{G}$. Este fato explica o aumento significativo no triênio 2009-2011 - que sucedeu a descoberta do Pré-Sal -, e a queda no triênio seguinte - tanto no volume de gastos sobre a receita, quanto no total de firmas engajadas em esforços de P\&D -, que tem vínculo com a diminuição significativa do preço internacional do petróleo no período.

Esta relação estreita entre esforços em P\&D e o setor de Petróleo e Gás no ERJ é reforçada pelos dados divulgados pelo boletim mensal da $\mathrm{ANP}^{2}$ sobre a aplicação dos recursos provenientes da cláusula de $\mathrm{PD} \& \mathrm{I}^{3}$ e do Programa de Formação Recursos Humanos da Agência. Segundo a última edição do Boletim ${ }^{4}$, entre 2006 e 2016 a ANP concedeu autorizações prévias para 1.429 projetos, que totalizavam recursos na ordem de 4,6 bilhões de reais. Do total de projetos, o Rio de Janeiro concentrava mais de um terço do total (509 projetos), mais do que o dobro de São Paulo (241 projetos). Somente a UFRJ era responsável por 277 projetos. Ademais, o ERJ teve cerca de 1,3 milhão de reais em recursos autorizados, o que representava quase $30 \%$ do total. Neste aspecto, a UFRJ também se destaca, ao ser o destino de 11,34\% destes recursos. Por fim, vale ressaltar ainda que das 724 unidades de pesquisa credenciadas pela ANP aptas a executar projetos com recursos oriundos da cláusula de PD\&I, 287 estão no ERJ - 39,6\% do total. Somente a UFRJ conta com 134 unidades de pesquisa credenciadas (ANP, 2017). Estes dados reforçam o peso do setor de P\&G nos esforços de P\&D realizados no Estado.

Um estudo feito por La Rovere et al. (2015) mostrou ainda que no Estado do Rio de Janeiro há uma alta concentração da oferta de cursos para o setor de Petróleo e Gás. Os autores mapearam 978 cursos que atendem direta ou indiretamente as demandas por capacitação do setor. O município do Rio de Janeiro concentra quase $80 \%$ do total de cursos superiores e de pós-graduação lato sensu. Apesar da oferta de cursos técnicos ainda ser incipiente, a conclusão do estudo é a de que o ERJ se apresenta atualmente como um "centro de excelência" nacional de formação para todos os níveis de escolaridade exigidos pelo setor de Petróleo \& Gás.

Grosso modo, os dados mostram uma forte especialização da economia fluminense em torno do setor de Petróleo e Gás nas últimas duas décadas. O ERJ, portanto, se tornou dependente da cadeia do $\mathrm{P} \& \mathrm{G}$, que além de representar grande parte do valor adicionado da indústria, também direcionou as atividades de P\&D e a oferta de capacitação no Estado. Esta dependência limitou a atividade de P\&D do sistema de inovação fluminense, que ficou cada vez mais restrita ao esforço de grandes empresas, sobretudo ligadas ao setor de $\mathrm{P} \& \mathrm{G}$, e tornou-se instável, variando de acordo com os ciclos de grandes investimentos e com as flutuações do preço do petróleo. A conjugação destes elementos indicam efeitos de lock-in no sistema de inovação fluminense, cada vez mais "aprisionado" em uma trajetória de desenvolvimento direcionada e orientada para o setor de P\&G.

Diante deste quadro, um entrevistado do IEL ressalta a importância do programa Compra Rio ${ }^{5}$ para o ERJ, como forma de estimular a criação e consolidação de pequenas e médias empresas que possam atender às grandes empresas e diminuir a dependência da economia fluminense das mesmas.

E aí, outra coisa que (...) é importantíssima, pensando no Compra Rio: empresas que possam ser fornecedoras de âncoras aqui. Isso é maravilhoso. Isso aumenta muito a solução da âncora no próprio Estado do Rio, sem que ela tenha que trazer de fora. (Entrevistado 1 IEL, 2015).

\footnotetext{
${ }^{2}$ Agência Nacional do Petróleo, Gás Natural e Biocombustíveis: http://www.anp.gov.br/wwwanp/

${ }^{3}$ Esta cláusula obriga as empresas petrolíferas a investirem $1 \%$ do faturamento dos poços mais rentáveis em PD\&I.

${ }^{4}$ http://www.anp.gov.br/wwwanp/images/publicacoes/boletins-anp/boletim petroleo p-e-d/Boletim Petroleo e PD40-LM D.pdf

${ }^{5}$ Programa instituído pela Secretaria de Estado de Desenvolvimento Econômico, Energia, Indústria e Serviços, que tem por objetivo incrementar o volume de compras de produtos e serviços oferecidos no Estado do Rio de Janeiro, através de Rodadas e Encontros de Negócios que colocam, frente a frente, fornecedores e compradores, incentivando a melhoria do ambiente de negócios e possibilitando a criação de novos postos de trabalho.
} 


\subsection{Falhas de Aprendizado e Capacidade de Absorção das Firmas}

Como vimos anteriormente, os esforços de $\mathrm{P} \& \mathrm{D}$ das firmas fluminenses estão fortemente ligados à atuação de grandes empresas e são, em grande medida, orientados pelo setor de Petróleo e Gás. No entanto, se considerarmos o total dos gastos inovativos ${ }^{6}$ a situação do Rio de Janeiro é ainda mais dramática, estando aquém da média do Sudeste e do país. Considerando o percentual de firmas com gastos inovativos na indústria (ver Gráfico 4), no primeiro triênio o ERJ estava 5,28 p.p. abaixo da média do Sudeste e do Brasil; essa diferença cresce para 6,28 p.p. no segundo triênio, e atinge seu maior nível no triênio 2006-2008 - 8,35 p.p. No triênio 2009-2011, o Rio de Janeiro avançou 4 p.p. e se aproximou da média do Sudeste e do país. No entanto, no último triênio o desempenho fluminense registra uma queda significativa, em torno de 5,3 p.p., e se descola novamente da média do Sudeste e do Brasil.

Gráfico4: Firmas com Gastos Inovativos/Total das Firmas nas indústrias extrativas e de transformação no Brasil, Rio de Janeiro e Sudeste nos períodos 2001-2003, 2003-2005, 2006-2008, 2009-2011

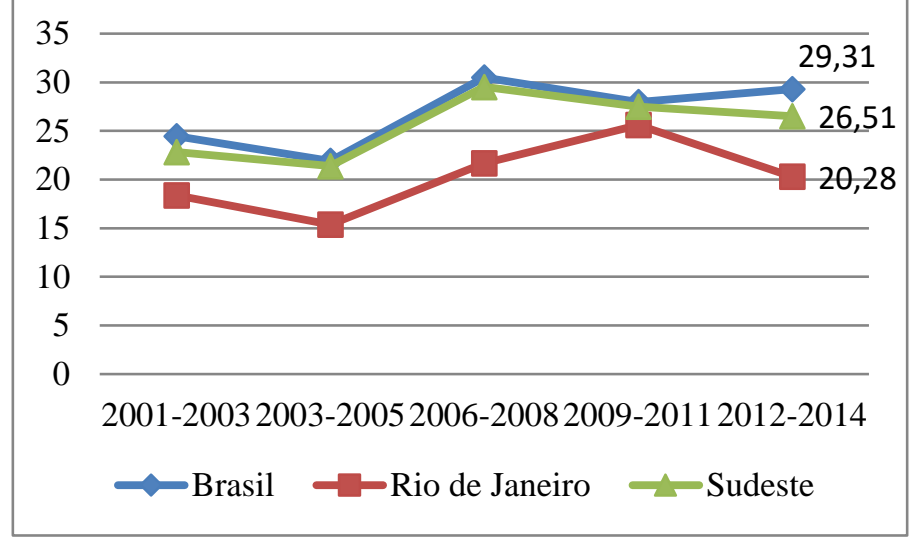

Fonte: PINTEC/IBGE

A análise do percentual de gastos inovativos sobre a receita total (ver Gráfico 5) reforça este cenário. Durante todo o período analisado, o Estado do Rio de Janeiro apresenta desempenho médio inferior ao do Sudeste e do Brasil - em torno de 1p.p. Nota-se que no triênio 2009-2011 há um movimento de subida do ERJ. Entretanto, este crescimento está diretamente relacionado com a grande aceleração dos gastos em $\mathrm{P} \& \mathrm{D}$, em detrimento de outros gastos inovativos, típicos de empresas de médio e grande porte. Esta hipótese é reforçada com a queda expressiva registrada no triênio seguinte, semelhante à queda que ocorreu nos gastos em atividades de P\&D. Cabe ressaltar que nos dois últimos triênios, os gastos em P\&D representaram aproximadamente $68 \%$ e $57 \%$ do total de gastos inovativos respectivamente.

\footnotetext{
${ }^{6}$ Além das Atividades internas de P\&D, incluem também: Aquisição externa de P\&D; Aquisição de outros conhecimentos externos; Aquisição de software; Aquisição de máquinas e equipamentos; Treinamento; Introdução das inovações tecnológicas no mercado; Projeto industrial e outras preparações técnicas para a produção e distribuição. (PINTEC, 2016, pp. 19-20).
} 
Gráfico5: Gastos Inovativos/Receita Total nas indústrias extrativas e de transformação no Brasil, Rio de Janeiro e Sudeste nos períodos 2001-2003, 2003-2005, 2006-2008, 2009-2011, 2012-2014

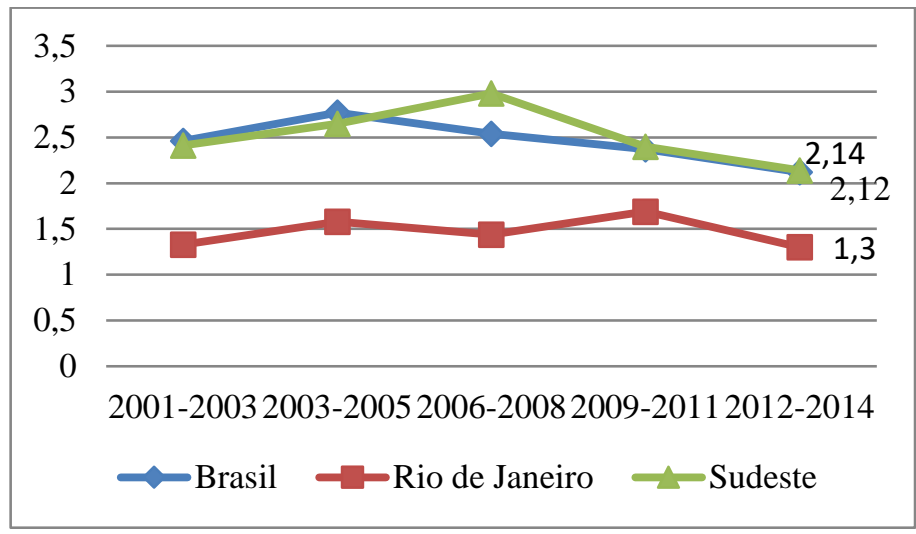

Fonte: PINTEC/IBGE

Em linhas gerais, observa-se que a concentração de gastos em P\&D em algumas grandes empresas contrasta com o desempenho negativo nos indicadores de esforços inovativos para o total da indústria fluminense. Além disso, podemos inferir que boa parte das empresas inovadoras não realiza gastos formais em $\mathrm{P} \& \mathrm{D}$, e sim outros tipos de gastos inovativos, sobretudo, aquisição de máquinas e equipamentos. No entanto, as evidências sugerem que estes esforços se encontram relativamente pouco difundidos entre as empresas que conformam a estrutura produtiva do Estado do Rio de Janeiro, reforçando a hipótese de que há dificuldades para se acelerar o processo de capacitação tecnológica do conjunto da indústria fluminense. De acordo com Brito e Marcellino (2014), o ERJ possui uma estrutura industrial que possui simultaneamente elevados esforços em $\mathrm{P} \& \mathrm{D}$ (conduzidos, sobretudo, por empresas de grande porte), e uma baixa densidade em termos de firmas inovadoras.

A fim de corroborar esta hipótese, destacaremos os dados sobre a taxa de inovação nas indústrias extrativas e de transformação (ver gráfico 6).Como podemos observar no gráfico abaixo, durante o período analisado, a taxa de inovação no ERJ esteve sistematicamente abaixo das encontradas no Sudeste e no Brasil como um todo. A evolução de todas elas é bem parecida, sendo bastante próximas no período 2009-2011. Contudo, no último triênio a taxa de inovação da indústria fluminense sofre uma queda significativa - cerca de 6,5 p.p. -, voltando ao patamar do triênio 20012003, e afastando-se sobremaneira da taxa de inovação média do Sudeste e do país.

Gráfico6: Taxa de Inovação nas indústrias extrativas e de transformação no Brasil, Rio de Janeiro e Sudeste nos períodos 2001-2003, 2003-2005, 2006-2008, 2009-2011, 2012-2014

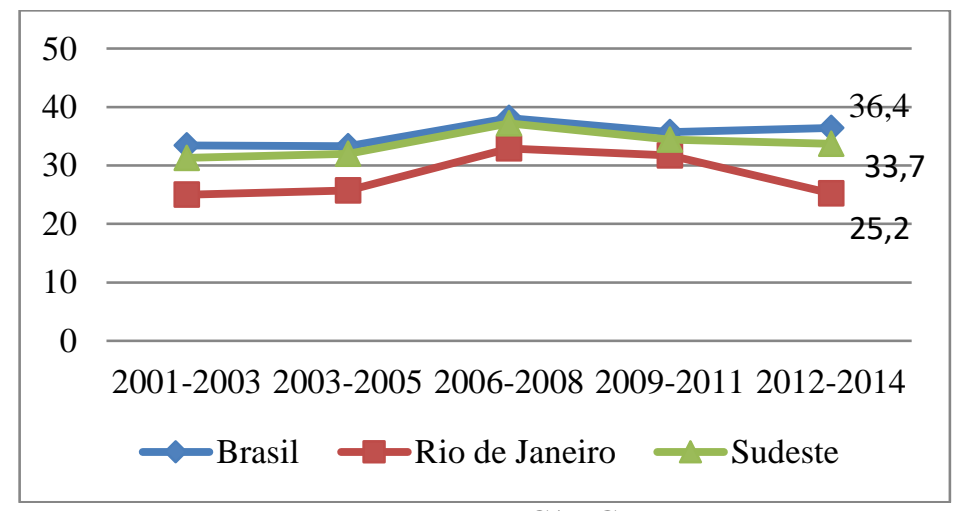

Fonte: PINTEC/IBGE

Os dados apresentados reforçam a percepção de que o sistema de inovação fluminense apresenta dificuldade em converter recursos humanos e financeiros em uma performance inovativa compatível. Este resultado evidencia as limitações nos processos de aprendizado das firmas que compõem o sistema de inovação fluminense, uma vez que os esforços de inovação são pouco 
difundidos, e a densidade de firmas inovadoras é baixa. Este diagnóstico é corroborado pelo Gerente da Área de Soluções e Inovações do SEBRAE:

\begin{abstract}
No nosso planejamento estratégico a gente identifica o seguinte: o comportamento (...) das pequenas empresas do Estado do Rio de Janeiro, quando a gente compara (...) com a de pequenas empresas de outros Estados, como Rio Grande do Sul, São Paulo, Minas Gerais, Santa Catarina, e fazemos um corte pra frente, pensando daqui há 10, 15, 20 anos, [identificamos que] a curva de crescimento das pequenas empresas do nosso Estado (RJ) começa a decair, e a curva de crescimento das empresas dos outros Estados começa a crescer. Ou seja, as pequenas empresas aqui no Rio de Janeiro estão com uma tendência de desenvolvimento ainda muito frágil. Estão desenvolvendo produtos e serviços de baixo valor agregado, de baixa tecnologia agregada, e com isso estão perdendo cada vez mais competitividade nos próximos anos. (Entrevistado 2 SEBRAE, 2015, grifo nosso).
\end{abstract}

Para complementar a análise, buscamos examinar o emprego de mestres e doutores - através da consulta à base de dados da RAIS/MTE -, visto que este é um bom indicador para investigar de que forma as firmas e regiões absorvem a mão de obra altamente qualificada formada pela infraestrutura científico-tecnológica. Supõe-se que quanto mais complexa a infraestrutura de C\&T, e mais diversificada a estrutura produtiva, sobretudo em setores de média e alta tecnologia, maior a probabilidade da região gerar postos de trabalho altamente qualificados, e assim empregar mestres e doutores. Estas características geralmente são encontradas em grandes metrópoles.

Até o final de 2015, o Estado do Rio de Janeiro empregava formalmente 29.086 mestres e 9.720 doutores, perfazendo um total de 38.806 profissionais. A região metropolitana concentrava neste ano quase $85 \%$ do total do emprego de mestres e doutores, valor superior ao da participação da região no total de empregos formais do Estado. O município do Rio de Janeiro, sozinho, abrigava 7 em cada 10 mestres e doutores empregados no ERJ. No entanto, observar os números absolutos de empregos de mestre e doutores, apesar de relevante, não é suficiente. Desta feita, é necessário analisar a distribuição destes metres e doutores nos diferentes subsetores ${ }^{7}$ definidos pela CNAE/IBGE, possibilitando apreender a dinâmica setorial da absorção destes profisssionais.

Ao observar os gráficos 7 e 8 , percebemos que os mestres e doutores estão em sua maioria empregados nos subsetores "Ensino" e "Administração Pública". A soma de ambos os setores ultrapassa $70 \%$ do total de empregos de mestres e doutores no conjunto do ERJ, na Região Metropolitana e no Interior do Estado. Se somarmos o subsetor "Administração Técnica Profissional", supera-se a marca de $80 \%$ do total de empregos de mestres e doutores na Região Metropolitana e no conjunto da economia fluminense. As exceções a este quadro são: na Região Metropolitana, o subsetor "Indústria Química"; e no Interior, o subsetor "Indústria Extrativa" em relação aos mestres, e os subsetores "Instituição Financeira", "Alojamento e Comunicação" e "Serviços Médicos, Odontológicos e Veterinários" no que se refere aos doutores.

\footnotetext{
${ }^{7}$ São eles: Indústria Extrativa Mineral; Produção de Mineral Não Metálico; Indústria Metalúrgica; Indústria Mecânica; Elétrico e Comunicação; Material de Transporte; Madeira e Mobiliário; Papel e Gráfica; Borracha, Fumo e Couros; Indústria Química, Indústria Têxtil; Indústria de Calçados; Alimentos e Bebidas; Serviços de Utilidade Pública; Construção Civil; Comércio Varejista; Comércio Atacadista; Instituição Financeira; Administração Técnica Profissional; Transporte e Comunicações; Alojamento e Alimentação; Serviços Médicos, Odontológicos, Veterinários; Ensino; Administração Pública; e Agricultura.
} 
Gráfico7: Participação (\%) de cada Subsetor (CNAE/IBGE) no Emprego de Mestres na Região Metropolitana, Interior e Estado do Rio de Janeiro (2015)

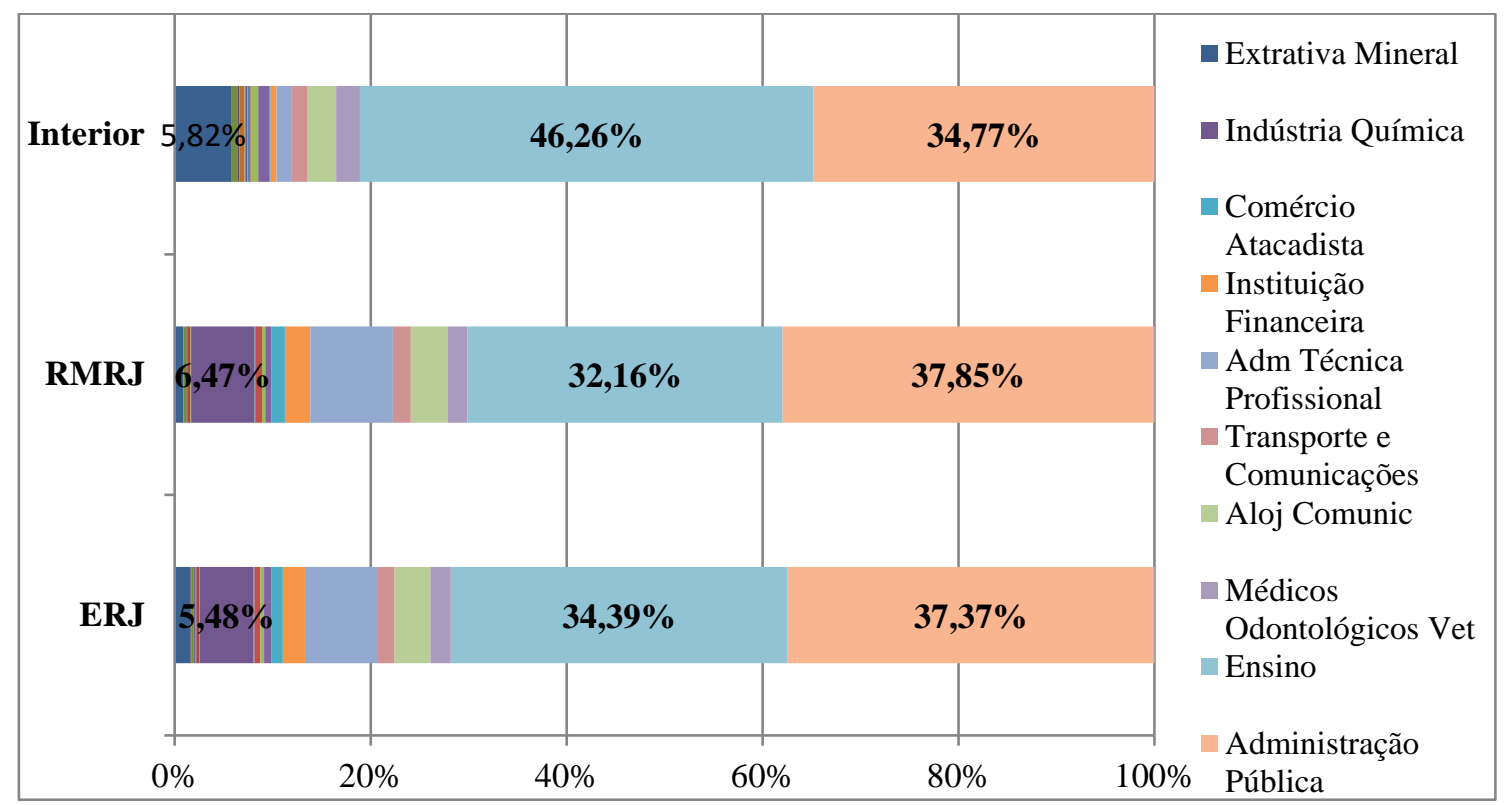

Fonte: Elaboração própria com base na RAIS/MTE

Gráfico8: Participação (\%) de cada Subsetor (CNAE/IBGE) no Emprego de Doutores na Região Metropolitana, Interior e Estado do Rio de Janeiro (2015)

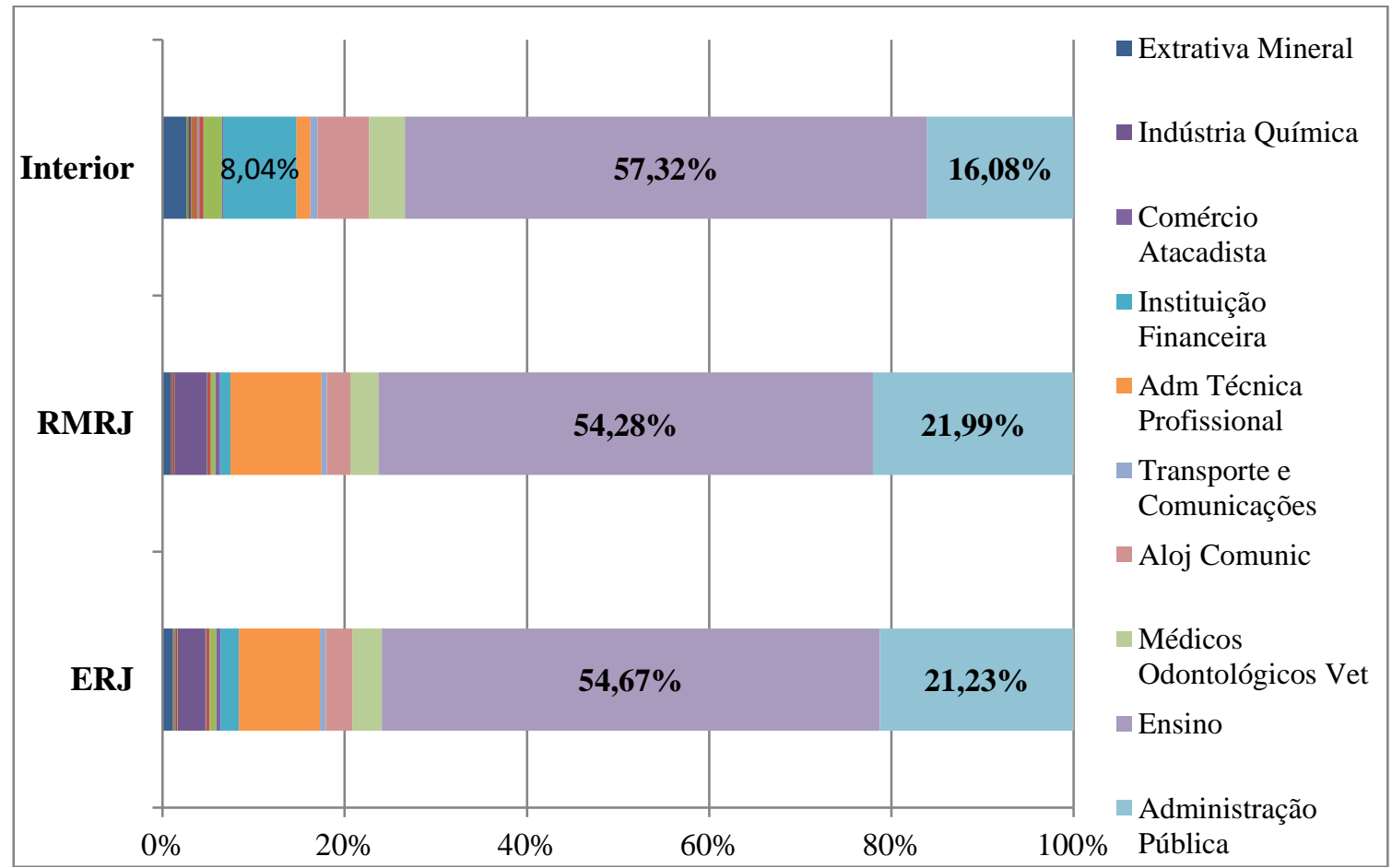

Fonte: Elaboração própria com base na RAIS/MTE

Os dados sinalizam a concentração de mestres e doutores na região metropolitana, e, sobretudo na capital do Estado, evidenciando a dificuldade do conjunto da economia em absorver estes profissionais. Além disso, nota-se que a maioria dos mestres e doutores está envolvida em atividades de "Ensino" e "Administração Pública", em detrimento do setor produtivo, levando ao consequente afastamento destes profissionais das atividades de desenvolvimento tecnológico. A despeito de algumas exceções, podemos afirmar que a maioria das empresas industriais não emprega mestres e doutores, restringindo o mercado destes profissionais altamente qualificados que acabam se refugiando no setor público, principalmente nas atividades ligadas ao Ensino e à 
Administração Pública. Neste sentido, é lícito supor que as firmas que compõem o sistema de inovação fluminense possuem restrições em suas capacidades de absorção.

\subsection{Falhas nas Complementaridades Dinâmicas}

As falhas nas complementaridades dinâmicas, apontadas por Malerba e Torrisi (2009) como um dos elementos a se considerar no desenho de políticas de inovação, ocorrem quando as instituições atuam de forma isolada e quando as organizações criadoras e difusoras de conhecimento não atuam em rede. Como apontado por Malerba e Vonortas (2009), as redes de inovação "são conceitos multidimensionais que envolvem diferentes tipos de atores, diferentes esferas de conhecimento, ciência e tecnologia, e podem se referir tanto a P\&D quanto a produção e marketing" (p.6). Vonortas (2009) acrescenta que as redes trazem benefícios relacionados ao maior acesso a informações, aumentando a capacidade de cognição e de aprendizado dos seus componentes, mas que também podem trazer efeitos de lock-in, limitando as possibilidades de inovação.

A reduzida capacidade de absorção das empresas do ERJ já mencionada e o baixo percentual de redes de inovação no total de redes de pesquisa denota a necessidade da criação de mais redes de inovação envolvendo empresas, institutos de pesquisa, universidades e diferentes órgãos públicos e do terceiro setor, bem como de iniciativas, por parte das instituições locais, de fortalecimento das redes já existentes.

Porém, as entrevistas realizadas com gestores de instituições de apoio à inovação apontam que até políticas que antecedem as políticas de apoio a redes de inovação, tais como políticas de criação de empresas de base tecnológica e startups, têm limites, por conta de falhas de informação:

As políticas relacionadas à criação principalmente de empresas de base tecnológica, de empresas que atuem dentro de setores mais estratégicos no Estado e no país como um todo, eu acho que ainda estão bem tímidas. Apesar de terem várias linhas bastante recentes, linhas que são pouco exploradas ainda, que a FINEP disponibiliza, o BNDES disponibiliza, ainda têm pouco acesso. Volta e meia a gente se depara com informações de recursos que não são acessados, porque faltam alguns projetos. (Entrevistado 1 - SEBRAE, 2015).

Há também um reconhecimento, por parte das instituições, de que as políticas de apoio a startups necessitam de monitoramento:

Eu acho que, em primeiro lugar, você tendo mais empresas sendo criadas, você também tem mais oportunidade de postos de trabalho. Eu acho que essa é uma grande demanda hoje, que o país precisa: criar postos de trabalho, justamente, alinhados à nova vertente futura que o mercado e o mundo vão pedir. (..) tem que dar um parêntese aí: "startups" sustentáveis tipo "startups triple bottom line": econômico, social e ambiental, mas principalmente econômico, tá? Não "Startup pinga-pinga" que entra na moda e morre um ano depois. Isso também não adianta nada. (Entrevistado 1 - IEL, 2105).

A constatação da falta de coordenação entre as instituições sugere que há dificuldades para se constituir redes de inovação:

$\mathrm{Na}$ realidade, os diversos entes estaduais, todos eles praticam alguma coisa de inovação, mas pouquíssimos se falam. E eu não sei se não se falam intencionalmente ou se não se falam porque talvez seja um problema de agenda. (...) O que eu reparei efetivamente é que na realidade as agendas são muito similares, o que acontece é uma assimetria de informação e uma desintegração das redes estaduais. (Entrevistado1 - FINEP, 2015, grifo nosso).

Mesmo quando há acordo entre as instituições localizadas no ERJ sobre de que forma implementar políticas de apoio às empresas, há dificuldades de conciliação de agendas e de orçamento:

(...) por exemplo, o governo do estado do Rio de Janeiro, através da Secretaria de Ciência e Tecnologia e Inovação (SECTI), lançou um edital de apoio às startups. Estão traduzindo a necessidade de se criar uma política de estímulo às startups no Estado do Rio de Janeiro. Então se associa o governo do estado, através da Secretaria de C,T\&I e da Secretaria de Desenvolvimento Econômico. As duas se unem, e a Secretaria de desenvolvimento econômico faz parte do conselho. Então o Secretário de Estado é que vem com essa 
bandeira. Só que ele tem várias bandeiras. Então eu imagino que não é uma tarefa das mais fáceis conseguir dosar qual que ele vai traduzir ali para ser discutida em termos de foco de atuação nosso. O orçamento é limitado.” (Entrevistado 2 - SEBRAE, 2015, grifo nosso).

O que acaba acontecendo, na prática, é que os objetivos das políticas vão se ajustando à medida que estas vão sendo implementadas:

\begin{abstract}
Algumas agências de fomento, como a FINEP, por exemplo, tem um foco mais em inovação. É difícil saber [como conciliar os objetivos das diferentes instituições] porque fazemos muita coisa, então em algum momento os objetivos se encaixam. Nós somos vários bancos dentro de um banco grande. Então as políticas sempre são compatíveis em algum grau. (Entrevistado 2 -BNDES, 2015).
\end{abstract}

Os resultados acima reforçam os achados de Porto et al. (2012), que apontou uma interação precária entre governo, universidades e empresas e diversas dificuldades resultantes, sendo as principais: baixa confiança entre os atores, ausência de cultura de cooperação e falta de informação por parte do empresariado dos benefícios potenciais de pertencimento a redes de inovação.

Conforme apontado por Malerba e Torrisi (2009), o desenvolvimento de complementaridades dinâmicas requer políticas de apoio que fortaleçam os laços entre os elementos do sistema regional de inovação e realizem um diagnóstico da demanda potencial por novas tecnologias que possam propiciar o surgimento de redes de cooperação.

\title{
5.4. Trade-offs entre inovação e difusão e entre desenvolvimento de novo conhecimento e aproveitamento do estoque de conhecimentos existente
}

Malerba e Torrisi (2009) sugerem que políticas voltadas ao fortalecimento de sistemas regionais de inovação se deparam com escolhas (trade-offs) que envolvem apostar nas competências já estabelecidas, promovendo a difusão de inovações, ou ampliar o leque de competências da região para torná-la menos vulnerável aos ciclos econômicos, aumentando assim a capacidade de geração de inovações. Cabe ressaltar que a aposta nas competências estabelecidas é condição necessária, mas não suficiente, para promover a difusão de inovações. A difusão depende também de uma articulação entre governo, empresas e instituições de ensino e pesquisa de modo a facilitar a chegada do novo conhecimento ao mercado.

No caso do ERJ, um levantamento no diretório de Grupos de Pesquisa do CNPq mostra que entre 2000 e 2016 houve um crescimento absoluto de grupos de pesquisa, porém em velocidade menor do que o crescimento dos grupos de pesquisa no Brasil (ver Tabela 1), o que indica uma perda do Estado na capacidade de geração de inovações.

Tabela 1: Grupos de Pesquisa do Estado do Rio de Janeiro - número absoluto e percentual em relação ao Brasil, 2000-2016

\begin{tabular}{|c|c|c|}
\hline Ano & Número Absoluto & \% em relação ao Brasil \\
\hline 2000 & 1922 & 16,3 \\
\hline 2002 & 2111 & 13,9 \\
\hline 2004 & 2786 & 14,3 \\
\hline 2006 & 2772 & 13,2 \\
\hline 2008 & 2779 & 12,2 \\
\hline 2010 & 3313 & 12,0 \\
\hline 2014 & 4147 & 11,7 \\
\hline 2016 & 4360 & 11,6 \\
\hline
\end{tabular}

Fonte: CNPq. Dados para 2012 não disponibilizados.

Entretanto, o percentual de grupos de pesquisa que declararam ter interações com pelo menos uma empresa saltou de 7,8\% em 2002 para 37,7\% em 2016 (ver Tabela 2). A média nacional no mesmo período saltou de8,4\% para 31,7\%. Assim, as interações entre grupos de pesquisa e empresas cresceram no ERJ em velocidade maior do que a média nacional. 
Tabela 2: Grupos de Pesquisa do Estado do Rio de Janeiro que declararam tem interação com pelo menos uma empresa - número absoluto e percentual em relação ao total, 2000-2016

\begin{tabular}{|c|c|c|}
\hline Ano & Número Absoluto & \% em relação ao Brasil \\
\hline 2002 & 165 & 7,8 \\
\hline 2004 & 259 & 9,2 \\
\hline 2006 & 264 & 9,5 \\
\hline 2008 & 286 & 10,3 \\
\hline 2010 & 358 & 10,8 \\
\hline 2014 & 1216 & 29,3 \\
\hline 2016 & 1645 & 37,7 \\
\hline
\end{tabular}

Fonte: CNPq. Dados para 2000 e 2012 não disponibilizados.

Apesar da aparente melhora nas condições de difusão de inovações, as fragilidades do sistema regional de inovação, encontradas por Porto et al. (2012)e as falhas de aprendizado e de coordenação institucional apontadas neste artigo sugerem que as possibilidades de difusão de inovações são limitadas e a capacidade de geração de inovações é muito reduzida. $\mathrm{O}$ estudo conduzido por Britto, Cassiolato e Marcellino (2015) sugere que a melhoria do desempenho das indústrias fluminenses no que se refere à capacidade de inovação depende de mais apoio das instituições localizadas na região e estímulo à intensificação das interações e fluxos de transferência tecnológica.

A questão que se coloca é como estabelecer uma política de aproveitamento do estoque de conhecimentos existente. Estudo realizado por La Rovere et al. (2015) mostrou uma expressiva oferta de cursos de nível superior cuja formação está diretamente relacionada às atividades industriais consideradas estratégicas para o ERJ: 72 cursos na área de Petróleo \& Gás, 58 cursos na área Farmacêutica, 55 cursos na área de Construção Naval, 41 cursos na Metal-Mecânica, 27 cursos para a indústria de Bebidas. Se acrescentarmos a estes cursos os cursos de formação acessória (gestão de negócios, tecnologias de informação, etc.), chega-se a uma oferta que varia de 886cursos para a indústria de metalurgia e metal-mecânica a 974 cursos para a indústria de petróleo e gás. Entretanto, as indústrias que demandam estes cursos estão dispersas geograficamente e foram duramente afetadas pela atual crise do ERJ, levando os egressos destes cursos a se colocar em outras ocupações. Outra questão que coloca desafios à definição de políticas é como aproveitar competências estabelecidas que não têm vínculos claros com o setor produtivo no ERJ. Por exemplo, Porto et al. (2012) apontam uma forte competência do Estado na área de saúde que poderia servir de catalisador para o desenvolvimento de inovações caso houvesse a necessária articulação entre os atores do sistema de inovação fluminense.

\section{CONSIDERAÇÕES FINAIS: ELEMENTOS PARA UMA POLÍTICA DE APOIO AO SISTEMA DE INOVAÇÃO DO ESTADO DO RIO DE JANEIRO}

Este artigo pretendeu levantar os principais elementos de uma política estadual de inovação como contribuição para a agenda de políticas públicas ERJ, que segundo Osorio et al. (2015) carece de uma reflexão mais aprofundada e de uma melhor articulação entre políticas.

Com base na discussão acerca das falhas sistêmicas do sistema de inovação fluminense, podemos propor alguns elementos para uma política de apoio à inovação no Estado do Rio de Janeiro. Em primeiro lugar, constatamos que o ERJ tem limites para transformar sua base de competências científicas em competências para inovar. Além destes limites, o peso de empresas grandes como a Petrobras na atividade inovadora configuram efeitos de lock-in, ao direcionar o desenvolvimento de inovações para o setor de petróleo e gás.

Há, portanto, falhas nos processos de aprendizado e na capacidade de absorção das firmas fluminenses. Uma política de apoio ao sistema estadual de inovação deveria se centrar na diversificação da atividade inovadora e na melhoria da capacidade inovativa das empresas, sobretudo as de menor porte. A concentração das atividades de capacitação na região metropolitana 
aponta para a necessidade do fomento de interações entre empresas e instituições de ensino localizadas no interior e do fortalecimento destas últimas.

No que se refere às complementaridades dinâmicas, os limites das políticas de apoio ao empreendedorismo sugerem que é necessária uma política que articule as diversas instituições de fomento em uma rede que possa não apenas identificar áreas onde inovações podem ser desenvolvidas como também articular ações coordenadas para o desenvolvimento de ativos complementares. Cabe, portanto, ir além das ações de provimento de soluções tecnológicas, que apesar de serem importantes podem se tornar pontuais e específicas. Seria necessário aproveitar a experiência do funcionamento de redes já existentes no ERJ para propor iniciativas articuladas que envolvam não apenas empresas e instituições de ensino e pesquisa como também instituições de fomento à inovação. Não basta aproveitar o estoque de conhecimentos disponível nas instituições de ensino e pesquisa, cabendo também promover o desenvolvimento de novas competências. Cabe também realizar a identificação e o fomento de novas tecnologias que possam articular os atores já estabelecidos em redes de cooperação.

Finalmente, os dados sobre apresentados neste artigo sugerem que o ERJ vem apostando mais no aproveitamento de conhecimentos existentes do que no desenvolvimento de novos conhecimentos. Assim, cabe desenhar uma política de apoio que contemple a promoção de empreendedorismo dentro das empresas e que aumente o fomento à inovação nas instituições de ensino e pesquisa.

\section{REFERÊNCIAS BIBLIOGRÁFICAS}

AGÊNCIA NACIONAL DO PETÓLEO, GÁS NATURAL E BIOCOMBUSTÍVEIS. Boletim ANP: Petróleo e P\&D. Edição nº 40, janeiro, 2017.

BOSCHMA, R. Evolutionary economic geography and its implications for regional innovation policy. Papers in Evolutionary Economic Geography (PEEG) 9: 1-33, 2009.

BOSCHMA R. A.; FRENKEN, K. Some notes on institutions in evolutionary economic geography. Economic Geography 85: 151-158, 2009.

BRITTO, J; MARCELLINO, I. S. Especialização produtiva e dinamismo inovativo da indústria fluminense: desafios e potencialidades para o desenvolvimento regional. Relatório de Pesquisa. Rio de Janeiro: UFF/ UFRJ, 2014.

BRITTO, J; CASSIOLATO, J.E; MARCELLINO, I. S. Especialização produtiva e dinamismo inovativo da indústria fluminense: desafios e potencialidades para o desenvolvimento regional. In: Osorio, M.; Melo, L.M.; Versiani, M.H; Werneck, M.L. (orgs). Uma agenda para o Rio de Janeiro: Estratégias e Políticas Públicas para o Desenvolvimento Socioeconômico. Rio de Janeiro: FGV: 2015.

CASSIOLATO, J. E.; LASTRES, H. M. M. Sistemas de Inovação e Desenvolvimento: as implicações de política. São Paulo em Perspectiva v. 19, n. 1, p. 34-45, 2005.

COENEN, L.; ASHEIM, B.; BUGGE, M.; HERSTAD, S. Advancing regional innovation systems: What does evolutionary economic geography bring to the policy table? In: Environment and Planning C: Government and Policy $0(0) 1-21,2016$.

COOKE P. Regional innovation systems: competitive regulation in the new Europe. In: Geoforum 23(3), 365-382, 1992.

COOKE, P.; DE LAURENTIS, C; TODTLING, F.; TRIPPL, M. Regional Knowledge Economies - Markets, Clusters and Innovation. Cheltenham, U.K: Edward Elgar, 2007.

FEDERAÇÃO DAS INDÚSTRIAS DO ESTADO DO RIO DE JANEIRO - FIRJAN. Visões de futuro: Potencialidades e desafios para o Estado do Rio de Janeiro nos próximos 15 anos. FIRJAN, Rio de Janeiro, 2014. 
FELDMAN M. P.; KOGLER D. F. Stylized facts in the geography of innovation. In: HALL B.; ROSENBERG N. (Eds) Handbook of the Economics of Innovation, pp. 381-410. Elsevier, Oxford: 2010.

FREEMAN, C. Technology policy and economic performance: Lessons from Japan. London, Pinter Publishers, 1987.

GERTLER, M.; LEVITTE, Y. Local nodes in global networks: The geography of knowledge flows in biotechnology innovation. In: Industry and Innovation 12(4): pp. 487-507, 2005.

GIULIANI, E. The structure of cluster knowledge networks: Uneven and selective, not pervasive and collective. DRUID Working Paper 2005-11, 2005.

GRABHER, G. Yet another turn? The evolutionary project in economic geography. In: Economic Geography 85, 119127, 2009.

HASENClEVER, L.; PARANHOS, J. \& TORRES, R. Desempenho Econômico do Rio de Janeiro: Trajetórias Passadas e Perspectivas Futuras. In: DADOS - Revista de Ciências Sociais, Rio de Janeiro, vol. 55, n. 3, 2012, pp. 681 a 711.

KOGLER, D. F. Evolutionary Economic Geography -Theoretical and Empirical Progress.In: Regional Studies, Vol. 49, No. 5, 705-711, 2015.

LA ROVERE, R.L.; PARANHOS, J. Os investimentos no estado do Rio de Janeiro e seus efeitos sobre as micro e pequenas empresas. Relatório Técnico elaborado para o Observatório de Micro e Pequenas Empresas do IETS. Rio de Janeiro:SEBRAE/RJ, 2011. Disponível em http://arquivopdf.sebrae.com.br/uf/rio-de-janeiro/sebrae-no-rio-dejaneiro/estudos-e-pesquisas/estudo.pdf

LA ROVERE, R.L. (coord.) Condições de capacitação empresarial e os ambientes de inovação no Estado do Rio de Janeiro. Relatório Técnico para a FAPERJ (Edital 28/2012). Rio de Janeiro: IE/UFRJ, 2015.

LESSA, C. O Rio de todos os Brasis: uma reflexão em busca de auto-estima. Rio de Janeiro: Record, 2000.

LUNDVALL, B-A (Ed.). National innovation systems: towards a theory of innovation and interactive learning. London: Pinter, 1992.

LUNDVALL, B- $\AA$, JOHNSON, B.; ANDERSEN, E; DALUM, B. National systems of production, innovation and competence building. In: Research Policy 31, p. 213-231, 2002.

MALERBA, F; TORRISI, S. La Politica Pubblica. In: MALERBA, F. (org.) Economia dell Innovazione. Roma: Carocci Editore, 2009.

MALERBA, F; VONORTAS, N.S. Innovation networks in industries and sectoral systems: an introduction. In: MALERBA, F; VONORTAS, N.S. Innovation networks in industries. Chelteham, UK: Edward Elgar, 2009.

MARCELLINO, I.S.; AVANCI, V. L.; BRITTO, J. O Sistema Regional de Inovação Fluminense: características, desafios e potencialidades. Cadernos do Desenvolvimento Fluminense, Rio de Janeiro, n.2, julho/2013.

MASKELL, P.; MALMBERG, A. The competitiveness of firms and regions: 'ubiquitification' and the importance of localized learning. In: European Urban and Regional Studies 6, 9-25, 1999.

NATAL, J. Inflexão econômica e dinâmica espacial pós-1996 no Estado do Rio de Janeiro. In: Nova Economia, Belo Horizonte, 14 (3) pp. 71-90, setembro-dezembro/2004.

OSÓRIO, M. Economia, desenvolvimento e caminhos para o Rio de Janeiro. In: Revista de Economia Fluminense, v. VII, p. 13-17, 2013.

. Desafios para a Metrópole Carioca. Rio Pesquisa (FAPERJ), v. 1, p. 11-13, 2014. 
OSORIO, M; MELO, L.M.M; VERSIANI, M.H; WERNECK, M.L. Desafios para o Desenvolvimento Socioeconômico do Rio de Janeiro. In: In: Osorio, M.; Melo, L.M.; Versiani, M.H; Werneck, M.L. (orgs). Uma agenda para o Rio de Janeiro: Estratégias e Políticas Públicas para o Desenvolvimento Socioeconômico. Rio de Janeiro: FGV: 2015

PESQUISA DE INOVAÇÃO TECNOLÓGICA: 2014. Coordenação da Indústria - Rio de Janeiro: IBGE, 2016.

PORTO, G.; KANNEBLEY JR., S.; DIAS, A. \& RADAELLI, V.O Sistema Estadual de Inovação do estado do Rio de Janeiro: uma contribuição ao diálogo de políticas entre o governo do Estado do Rio de Janeiro e o Banco Interamericano de Desenvolvimento. BID, 2012.

SANTOS, A. Economia fluminense: Superando a perda de dinamismo? In: Revista Rio de Janeiro, n. 8, p. 31-58, set./dez. 2002.

SOBRAL, B. Metrópole do Rio e Projeto Nacional: Uma estratégia de desenvolvimento a partir de complexos e centralidades no território. Ed. Garamond, Rio de Janeiro, 2012.

A Falácia da "inflexão econômica positiva": algumas características da desindustrialização fluminense e do "vazio produtivo" em sua periferia metropolitana. In: Cadernos do Desenvolvimento Fluminense, n. 1, Rio de Janeiro, fevereiro, 2013.

A evidência da estrutura produtiva oca: o Estado do Rio de Janeiro como um dos epicentros da desindustrialização nacional. In: NETO, A. M.; CASTRO, C. N.; BRANDÃO, C. A. (orgs.) Desenvolvimento regional no Brasil: políticas, estratégias e perspectivas. Rio de Janeiro: IPEA, 2017

TÖDTLING, F.; TRIPPL, M. One size fits all? Towards a differentiated regional innovation policy approach. In: Research Policy, 34, pp. 1203-1219, 2005.

VONORTAS, N. Innovation networks in industry. In: MALERBA, F; VONORTAS, N.S. Innovation networks in industries. Chelteham, UK: Edward Elgar, 2009. 